World Lumen Congress 2021 | May 26-30, 2021 |

Iasi, Romania

\title{
Increasing Self-Confidence in Students from Different Universities through Exercises in Body Technique and Dance Therapy
}

Vlad Teodor GROSU, Hanna Imola VARI, Mircea

Nicolae ORDEAN, Gheorghe BALINT, Radu Adrian ROZSNYAI, Emilia Florina GROSU

https://doi.org/10.18662/wlc2021/28

How to cite: Grosu, V.T., Vari, H.I., Ordean, M.N., Balint, G., Rozsnyai, R.A., \& Grosu, E.F. (2021). Increasing Self-Confidence in Students from Different Universities through Exercises in Body Technique and Dance Therapy. In A. Sandu (vol. ed.), Lumen Proceedings: Vol. 17 World Lumen Congress 2021 (pp. 291-307). Iasi, Romania: LUMEN Publishing House. https://doi.org/10.18662/wlc2021/28 


\title{
Increasing Self-Confidence in Students from Different Universities through Exercises in Body Technique and Dance Therapy
}

\author{
Vlad Teodor GROSU1 1 , Hanna Imola VARI², \\ Mircea Nicolae ORDEAN³, Gheorghe BALINT4, \\ Radu Adrian ROZSNYAI ${ }^{5}$, Emilia Florina GROSU6
}

\section{Abstract}

Objectives of this article refer to ways to increase self-confidence in students from different universities in Transylvania manifested by the values of self-depreciation, infatuation and selfesteem. These are realized through the use of complex exercises on music in the form of dancetherapy and body technique.

Purpose: elaboration of an action strategy to modify the self-depreciation, self-esteem, infatuation. Hypothesis: by introducing the exercises of body technique and dance-therapy, the aim is to modify the components of the ASSI psychological test: self-depreciation, infatuation and self-esteem

Material and Methods: statistical processing was performed with the program Stats Direct v.2.7.2. The graphical representation of the results was done with the Excel application (from the Microsoft Office 2010 package). The tests used are: ASSI and an intervention program based on exercises in body technique and dance therapy.

The subjects participating in the experiment with a duration of 6 months by 200 students at the Technical University Cluj-Napoca, and the extension from Baia-Mare and from the Academy of Music "Gheorghe Dima" from Cluj-Napoca.

The period: of development was between October 2019 and March 2020.

\footnotetext{
1 Department PhD - Posdoct: Doctoral school FEFS, Faculty of Physical Education and Sport "Babeş - Bolyai University", Cluj - Napoca, Romania. Department work: Mecatronics and machines dynamics, Faculty of Automotive, Mechatronics and Mechanical Engineering, Technical University, Cluj - Napoca, Romania, vtgrosu@gmail.com

2 Department PhD Doctoral school FEFS, Faculty of Physical Education and Sport "Babeş Bolyai University", Cluj - Napoca, Romania, hanna imola@yahoo.com

${ }^{3}$ Department PhD Doctoral school FEFS, Faculty of Physical Education and Sport "Babeş Bolyai University", Cluj - Napoca, Romania, ordean.mircea@yahoo.com

${ }^{4}$ Faculty of Movement, Sports and Health Sciences, Vasile Alecsandri University, Bacău, Romania, gyuri68@hotmail.com

5 National Academy of Music "Gheorghe Dima", Cluj - Napoca, Romania, radurozsnyai@yahoo.com

${ }^{6}$ Doctoral school FEFS, Faculty of Physical Education and Sport "Babeş - Bolyai University", Cluj - Napoca, Romania, emiliaflorina.grosu@gmail.com
} 
The results: of this study are due to the intervention program through exercises in body technique and dance therapy performed by the experimental group compared to the control group. In the case of $A-S N$ it is a good correlation but of the opposite direction, which means that if $(A)$ self-depreciation decreases then (SN) self-esteem increases. In the case of I-SN it is an acceptable correlation and of the same meaning, which means that if (I) the infatuation increases and (SN) the self-esteem increases, were observed statistically significantly significant differences between the two times $(p<0.001)$.

Conclusions: Statistically significant differences were observed in the indicators of the ASSI tests (self-depreciation, self-esteem, infatuation) which indicates, that our intervention program in the preliminary study had a positive and measurable impact on students in terms of improving selfdepreciation and infatuation, as well as increasing self-esteem.

Keywords: Dance-therapy, body technique, self-depreciation, self-esteem, infatuation

Problem statement: numerous studies of students show positive changes in their behavior. Italian researchers have investigated the role of dance in the educational process. Because dance reflects either the physical and mental aspect, or the emotional and cognitive one, it can teach children to discover their still untapped potential, raising their self-awareness. In addition, the flexibility that dance brings allows the connection primarily with music, but also with other disciplines thus facilitating their connection and contributing to the achievement of a global vision of knowledge (Candela et al., 2013).

An educational program structured over 16 weeks, combined with dance therapy, seems to have a positive effect on the quality of life of obese people (Allet et al. 2017). Dance is more than a therapy, it can offer more than therapeutic benefits, the researchers reaching this conclusion by analyzing Parkinson's disease and applying therapeutic dance to patients (Rocha et al., 2017). Students who practiced dance reported significantly greater physical, cognitive, and social benefits than novice dancers. They also showed signs of improving their mood. Traditional Scottish dance can have the effect of delaying the signs of aging functional abilities in women, and simple physical activity can help maintain a correct posture. In both groups the balance and body composition remained the same (Dewhurst et al., 2014).

The practice of dance activates both motor and sensory circuits. Therefore, when an individual dances, the brain is stimulated by both the sound of music and dance movements. PET scanning showed regions of the brain that become activated during dance learning, including the motor cortex, somatosensory cortex, and cerebellum (Duberg, 2012). The benefits of dancing on the brain include improved memory and neural connections. 
In a study by Giovagnoli (2013), entitled Complementary Therapies in Medicine, the effects of active music therapy (AMT) in knowledge and behavior in chronic vascular encephalopathy are described. Cognitive performance, mood, interpersonal interaction and perceived abilities were assessed using neuro-psychological and psycho-behavioral measurements. After AMT, the cognitive profile was improved in attention, visuomotor coordination, and verbal and spatial memory. These positive changes were confirmed after 3 months. An increase in interpersonal interaction and consistent reductions in anxiety were also observed (Giovagnoli \& Oliveri, 2013). In an article by (Hackett, 2013), we find that music therapy provides conditions that can intentionally stimulate communication and increase opportunities for social interaction.

Dance therapy (DT) is the psychotherapeutic use of movement and dance for intellectual, emotional and motor support of the body (Ekman et al., 1998). As a way of creative artistic therapies, DT aims at the correlation between movement and emotions (Schore, 1994). Self-esteem gathers the dimensions of self-confidence and self-esteem. There is also talk of involving self-acceptance in the formation of self-esteem. The aspect of selfesteem aims at two directions: the opinion or feedback of others (extrinsic dimension), and the feeling of ability, competence in achieving goals or solving problems by the individual to accomplish tasks - intrinsic dimension (Humphreys, 2006).

The Self - Adams and Berzonsky (2009) define the self as an important component of the personality that is analyzed by several disciplines (psychology, sociology), and involves a range of associated concepts such as self-identity, self-image, self-concept, consciousness. self and self-concern (Adams \& Berzonsky, 2009). The self can be defined as a multitude of beliefs and images about our own person. Taylor \& Brown, (1994) proved that the image we create about ourselves is a deep part of our personality and means reflexivity, and this image is neither superficial nor changeable. The social dimensions of the self are described as follows: the concept of self includes psychic, physical features, is a mental schema, central to self, its identity or essence is the way we categorize our external behaviors and internal states, intimate thoughts being valued socially (Taylor and collab., 1994, quoted by Ilut,, 2001). The self has got two basic dimensions: the self - the existential self, the subjective component of the self, which provides a sense of awareness and identity of one's own existence and self - based on objective data that circumscribe physical data, cognitive abilities and personality traits (James, 1980).

The objectives of this research refer to ways to increase selfconfidence in students from different universities in Transylvania manifested 
by the values of self-depreciation, infatuation, and self-esteem. These are realized through the use of complex exercises on music in the form of dance-therapy and body technique. Applying artistic techniques improves students' results and optimizes their behavior. By applying systems of specific means, the aim is to change the dysfunctional negative emotions before and after the dance: stress, anxiety, sadness, guilt. Positive emotions such as self-confidence and self-esteem increase. Knowing the multiple therapies that help to achieve human physical and mental well-being, we chose the intervention through dance as a method to help reduce stress and improve school results for young people aged 19-25. Therefore, we proposed an action system, an intervention plan that can be applied during physical education and sports classes, using the specific means of dance.

The purpose - elaboration of an action strategy to modify the selfdepreciation, self-esteem, infatuation:

We propose the elaboration of an action strategy for the reduction of stress through different artistic techniques, and the evaluation of the efficiency of the applied research methods. At the same time, we should determine the opportunity and efficiency of practicing dance in students aged 19-25 to improve self-confidence, self-esteem, as well as decrease selfdepreciation and infatuation.

The objectives proposed by us take into account the well-being of young people, more precisely we consider reducing stress by applying intervention plans based on a sequence of specific steps in contemporary ballet, classical dance, but also specific elements taken from rhythmic gymnastics and artistic gymnastics. Self-esteem is defined as a dimension that is constantly changing. It is related to the perception of one's own characteristics that shape one's own self. In a broad sense, an applied sense of self-esteem implies the essential condition of dealing with crises and paranormal and normative problems without being discouraged (Humphreys, 2007). If in 1961 the psychologist Goffman (1961) said that the self has got two components: self-image - picture of the self-containing specific data about a person such as physical appearance, experiences and preferences and self-esteem - evaluative components: axiological evaluation and internalized social judgments of one's personality traits (Adams \& Berzonsky, 2009). Today we can list a few concepts used and recognized: self-efficacy, self-perception, self-regulation or self-control, self-monitoring of the individual, self-strengthening, self-improvement, self-realization (Chelcea, 2006).

Hypothesis: by introducing the exercises of body technique and dance-therapy, the aim is to modify the components of the ASSI psychological test: self-depreciation, infatuation and self-esteem. It is 
assumed that different indicators of stress (anxiety, emotional distress, selfregulation, etc.) are dependent (modifiable) variables, which can be improved by applying an independent variable, as in our case the dance program.

The subjects, period of time and place: the subjects participating in the experiment with a duration of 6 months by 200 students of the Technical University Cluj-Napoca, and the extension from Baia-Mare and from the Music Academy "Gheorghe Dima" from Cluj-Napoca. The development of experiment was taken between October 2019 and March 2020.

Organization of the research: in this phase of our research we applied ways to reduce stress and dedicated tools. We have started to implement the intervention plan. The two groups (control and experimental) were tested at an interval of 6 months (initial testing and final testing).

Lot I (control) 100 students, did not benefit from dancing, but only from the actual physical education and sports classes, and were tested in the two moments of registration (initial phase and final phase), with the same devices used in the case of the experimental group. Both batches were tested with the tests: ASSI (Self-Esteem). Lot II, (experimental) benefited from physical education classes through specific dance steps, specially composed. In general, experimental research is the verification of the hypothesis. Participants from both groups were tested in the same time frame.

Material and Methods: statistical processing was performed with the program StatsDirect v.2.7.2. The graphical representation of the results was done with the Excel application (from the Microsoft Office 2010 package). The tests used were: ASSI and an intervention program based on exercises in body technique and dance therapy. ASSI questionnaire (Selfdepreciation, Self-esteem, Infatuation). The ASSI questionnaire is a standardized test for assessing self-esteem as an individual trait. This test targets both "normal" self-esteem (with lower or higher values) and the accentuated poles of this dimension: self-depreciation and infatuation.

Self-esteem renders the most evaluative component of the human self, and represents the emotional experience, the emotions that a person experiences when referring to his own person. (Constantin, 2004). Self-esteem is an assessment that is made by us. The evaluation that a person considers having, the degree of self-satisfaction (Harter, 1998). Rosenberg (1979), in his work, differentiates positive or high self-esteem from negative or low selfesteem, and defines it as a complex emotional and cognitive synthesis.

Owens (1993) defined two new components of self-esteem, namely: self-confidence and self-depreciation. Normal self-esteem is defined by an individual who self-evaluates closer to one of the two poles, namely: low self-esteem or high self-esteem. 
Music therapy means the use of music to improve health or functional outcomes. It is a creative artistic therapy, which consists of a process in which a therapist uses all the physical, emotional, mental, social, aesthetic and spiritual facets to help clients improve their physical and mental health, especially cognitive functioning, motor skills. , emotional development, communication, sensors and social skills and quality of life, using both active and receptive musical experiences such as improvisation, composition and discussion of music. Approaches used in music therapy that appeared from the field of music education include Orff-Schulwerk, Dalcroze eurythmy and the Kodaly method. Models that have developed directly from music therapy are neurological music therapy (NMT), Nordoff-Robins music therapy and the Bonny method - images and guided music (Davis et al., 2008).

Relaxation through colors and free movements http://www.tarshi.net/inplainspeak/author/arpita-bohra/. These intervention programs consist of a succession of movements involving balance and arching exercises as well as models of body wave structures.

Musical composition by Nikos Ignatiadis "Triumph" in slow tempo $(12 \times 8)$ time. We noted $12 \times 8$ for technical reasons, but the exercises, each one will be performed at least $4 \times 8$ on the main directions, repeating laterally 2 times. On the occasion of the exercises, the emphasis was on the correct position of the body and head, on the correct posture of the arms and the transition of the body from one position to another correctly.

8 -stroke structures are randomly linked to develop creativity in students

(1x8) 1-2. Movement with the displacement of the center of gravity type "Side body wave" completed in sitting on the heel 3-4. Standing, bend on the left leg with the left arm obliquely up and the right arm obliquely down, 5-6. Weight shift on both legs with knees bent at the same time as the large torso bends forward, with the back rounded and the head flexed. 7 . lateral flexion on the right leg with the right arm obliquely up and the left arm obliquely downwards, 8. Unbalance forward, "body wave" type forward

(2x8) 1-4. Moving the weight of the body from one leg to the other forward, such as the "Temps -lie" movement with the arms raised forward, with the arms bent and looking behind the arms. 5-8. Moving the weight from one leg to the other backwards, type "Temps -lie" backwards with the lowering of the arms bent backwards downwards.

(3x8) In pairs: $1-4$. Moving the weight of the body from one leg to the other type "Temps -lie" sideways to the right with the swinging of the arms bent in the frontal plane to the right. 5-8. Moving body weight from 
one leg to the other to the left, type Temps - lie lateral left with swinging the arms bent in the front to the left.

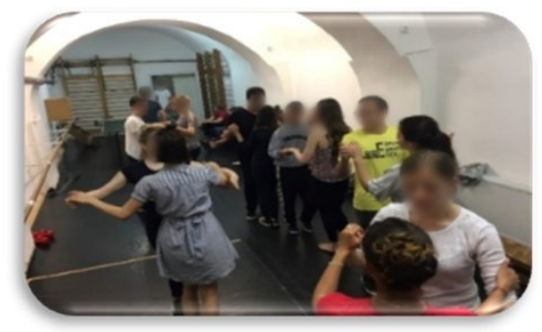

Fig.1. Balance movements in pairs

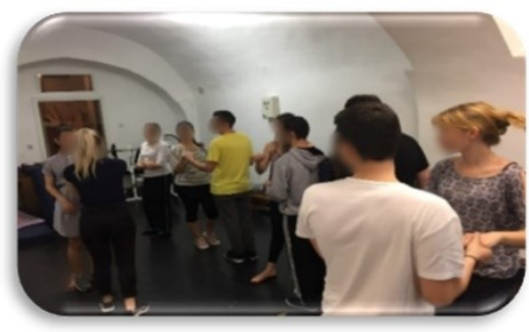

Fig.2. Exercises in pairs

(4x8) 1-2. Turn left with successive steps 360 degrees with arms folded up and 2 claps: $3-4$. Turn to the right with successive steps 360 degrees with arms up and 2 claps: 5-6. Maintaining static balance with the right leg bent, supported on the tip, with the arms close to the body. 7-8. Maintaining static balance with the left leg bent, supported on the tip and with the arms close to the body. We describe here all exercises.

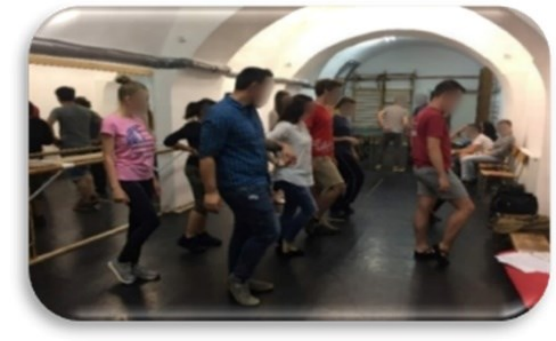

Fig.3. Maintaining the balance

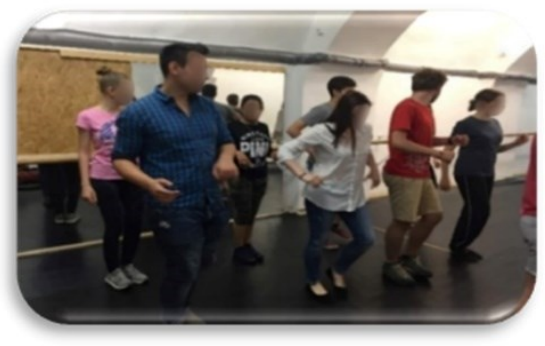

Fig.4. Static balance with bent leg

(5x8) 1-4, 2 right turns of the chains with the raising of the arms bent upwards.

5-8, 2 chained turns, chain type to the right with the arms raised bent up. (6x8) 1-4 "Body Wave" movement forward, with lower limbs bent with arms bent up, 5-8. "Body wave" type forward movement with finishing on the tips with the arms bent back and the knees bent.

(7x8) rhythmic clapping, touching a colleague on the right and then on the left.

(8x8) 1-4. Step with the right foot sideways to the right, step with the right foot and fix a balance position on the right foot with the left foot raised back, bent. 5-8. Step with the left foot sideways to the left, fixing a balanced position on the left foot with the right foot raised back, bent. (Grosu, 2009)

In the pilot study, these models of structures were chosen randomly and repeated by the experiment group 3 times, both at the beginning of 
physical education classes, after warm-up and at the end of physical education classes, in the last minutes. Number of sports hours per week: 2 (Tuesday and Friday). The control group benefited from the same sports class but without performing these exercises.

\section{Models of structures in swings:}

A. From the standing position: 1 standing; 2 . bend the right leg with the right arm bent obliquely upwards and the left arm bent obliquely downwards; 3. passing the weight on both legs with the knees bent simultaneously with the great bending of the torso forward, with the back rounded and the head in flexion. 4. lateral flexion on the left leg with the left arm obliquely upwards and the right arm bent obliquely downwards.

Standing with legs apart: arms side right: 1 - side step to the right followed by swinging the torso and arms in a horizontal arc from right to left, with slightly bending the knees, 2. completed with a 90 degrees turn to the left standing on the left leg, the right back on the tip, by time-type movement; 3-4. return to the starting position and move to the right by temps-lie movement.

On the knees: arms sideways to the right. 1. sitting on the heel, 2. swinging the trunk in a horizontal arc, from right forward to left and back on the knees, once the balance is completed.

Left costal position: support on the left forearm: $1-2$. balance of the right leg up to the level of the ear, 3 - 4. lifting the pelvis from the ground and support on the left arm and the tip of the right foot, with the right arm forward. Repeat the structure to the left.

B. Moving complexes: Standing: 1 - 2. added chase step to the right; 3 - 4. 360 degrees turn on the right foot and then on the left, 5. cross step with the left foot in front, 6. swinging the right foot sideways, Grandbattement type with the right leg .; 7. cross step with the right foot in front, 8. return.

Standing: 1. harrows - wine to the right with arms outstretched forward to the left leg, 3. harrows - wine to the left with the left arm obliquely up and the right arm obliquely down, 4. return to the starting position.

Standing: 1 - 2. Change left chasse step with left foot, with sagittal rotation of the foot on the foot back up, stop on the right foot with the left foot back, stretched, 3 - 4. return, chasse back with the left foot and rotating the arms forward, down, back. 
Standing: 1. Long jump, 2. sissonne jump, landing on the right leg, 3. swinging the left leg and keeping it on the side while raising the arms up, 4 return to the IP, 5-8. the same movement on the left leg.

Sitting: Parachute exercise. Moving forward with the parachute raised to the shoulders, on the music, in slow tempo. Exercise used to increase self-confidence.

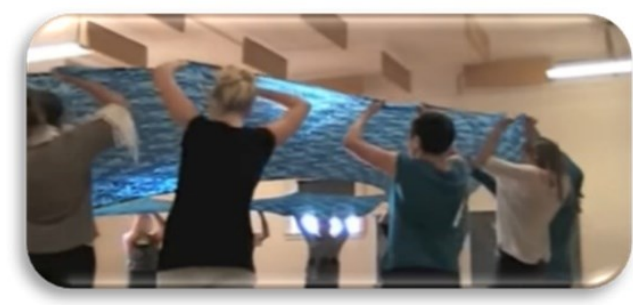

Fig.5. Exercises for increasing self-confidence

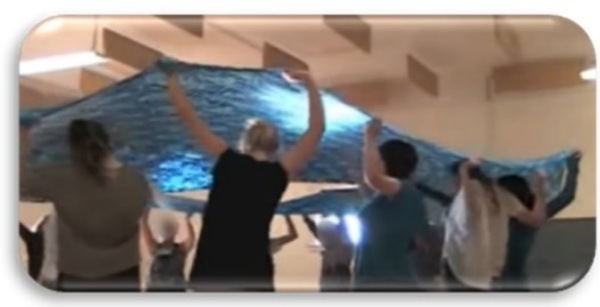

Fig.6. Movements with the parachute

Standing: 1. Bending the torso forward with the parachute raised over the head with the arms raised forward. Maintaining this position 8 times. Switching from sitting to sitting with flexing the knees and lying on your back, another 8 times, on music.

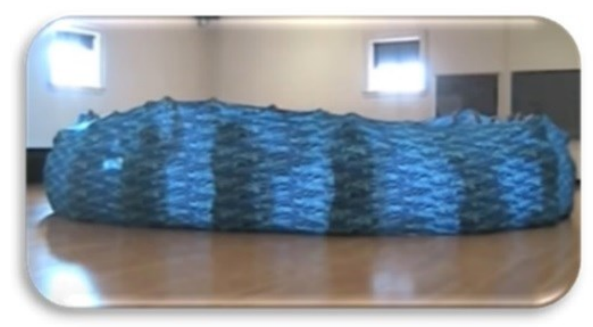

Fig.7 Lifting the parachute overhead Fig. 8 Lying on a parachute with your knees bent

Standing: 1. Lifting from dorsal to sitting on several 4 strokes, all at once and returning to dorsal on another 4 strokes. Slow tempo. It is used for teamwork, increasing self-confidence, and developing abdominal muscles. Sitting: Lifting the parachute above the head and slow running all in the same rhythm and tempo. It can be used to learn rhythm and tempo.

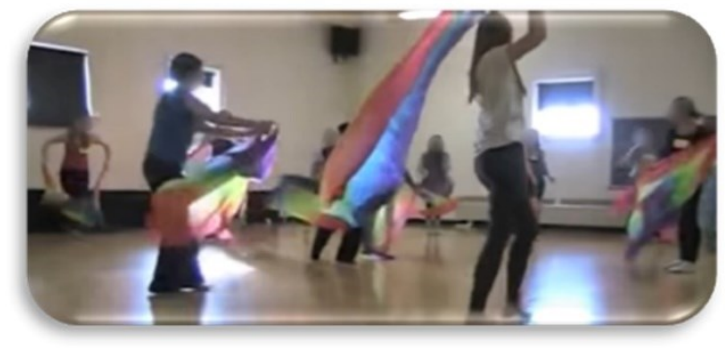

Fig. 9. Exercises with colored scarves 
Repeat the exercise identically to the right, with the left leg flexed with the left arm obliquely up and the right arm obliquely down; 3-4. passing the weight on both legs with the knees bent simultaneously with the large bend of the torso forward, with the back rounded and the head flexed. 5-8 turning the torso to the right, Guilbert, L. (2000).

Sitting with the arms on the right side with the scarf: 1-2. lateral step to the right followed by swinging the torso and arms in a horizontal arc from right to left, with the knees bent; 3-4. turning 90 degrees to the left while sitting on the left leg, right back bent, by moving the weight from one foot to the other type of time movement; 5-6. return to the starting position and move to the right by temps-lie movement.

Standing: 1-2. step added, chasse type to the right, 3-4. turn right 360 degrees on the right foot, 5. cross step with the left foot forward, 6. swing the right foot sideways as much as possible, 7 . cross step with the right foot forward, 8. return to PI

Standing: 1-2. grape - wine to the right with arms outstretched forward to the left leg, clapping with the neighbor on the left, 3-4. grape wine to the left with the left arm oblique up and the right arm oblique down, clapping with the neighbor on the right, 5-6. return to starting position.

Standing: 1-2. chasse forward with left foot, with arms rotated sagittal on foot back up, stop on right leg with left foot back, outstretched, 3-4. return to PI, 5-6. chasse back with left foot and rotating arms forward, down, back, 7-8. return to IP

The results of this study are due to the intervention program through exercises in body technique and dance therapy performed by the experimental group compared to the control group. In the case of A-SN it is a good correlation but of the opposite direction, which means that if (A) self-depreciation decreases then (SN) self-esteem increases. In the case of I$\mathrm{SN}$ it is an acceptable correlation and of the same meaning, which means that if (I) the infatuation increases and ( $\mathrm{SN}$ ) the self-esteem increases, were observed statistically significantly significant differences between the two times $(\mathrm{p}<0.001)$, tab.1

Table 1. ASSI questionnaire - studied lots and statistical significance

\begin{tabular}{|c|c|c|c|c|c|c|c|c|c|c|}
\hline \multirow{2}{*}{ Ind } & \multirow{2}{*}{ Time } & \multirow{2}{*}{ Lot } & \multirow{2}{*}{ Media } & \multirow{2}{*}{\multicolumn{2}{|c|}{ ES Median }} & \multirow{2}{*}{\multicolumn{2}{|c|}{ DS Min }} & \multirow{2}{*}{ Max } & \multicolumn{2}{|c|}{ Statistical significance $(p)$} \\
\hline & & & & & & & & & I-II & TI-TII \\
\hline \multirow{4}{*}{ A } & $\mathbf{T}$ & $\mathbf{I}$ & 6,13 & 0,2743 & 5 & 1,5025 & 4 & 9 & \multirow{2}{*}{$<0,0001$} & \multirow{2}{*}{$<0,0001$} \\
\hline & 11 & II & 4,20 & 0,3159 & 4 & 1,7301 & 1 & 9 & & \\
\hline & \multirow{2}{*}{ T2 } & $\mathbf{I}$ & 5,13 & 0,2701 & 5 & 1,4794 & 3 & 8 & \multirow{2}{*}{$<0,0001$} & \multirow{2}{*}{0,032} \\
\hline & & II & 3,13 & 0,2826 & 3 & 1,5477 & 1 & 7 & & \\
\hline $\mathbf{I}$ & T1 & $\mathbf{I}$ & 6,50 & 0,1962 & 6 & 1,0748 & 4 & 9 & 0,0669 & $<0,0001$ \\
\hline
\end{tabular}


Vlad Teodor GROSU, et al. | Lumen Proceedings 17 | WLC 2021

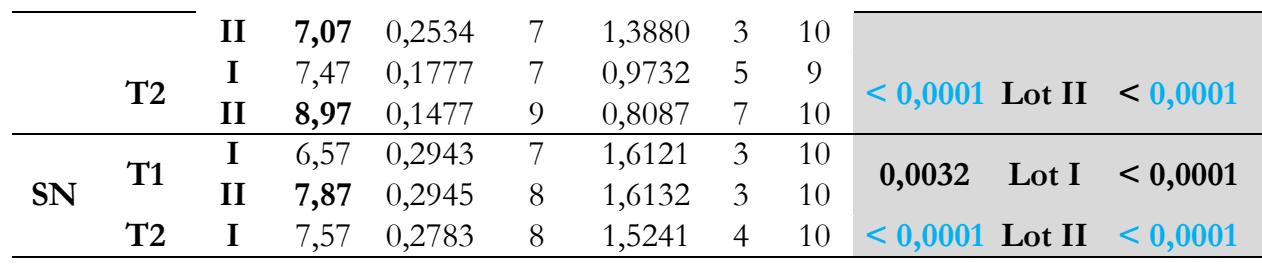

In the statistical analysis of the values for self-depreciation (A), for unpaired samples were observed statistically significantly significant differences between the two groups $(p<0.001)$ in both time points studied. In the statistical analysis for paired samples, statistically significant differences were observed between the two time points in both group I and group II ( $p$ <.001). We therefore observe a significant decrease in this value, marked in green in Table 1, which means that our intervention was useful to the experimental group in reducing their sense of self-depreciation, thus improving self-esteem.

As we can see in Table 1, in the statistical analysis of the values for infatuation (I) for unpaired samples were observed statistically significantly significant differences between the two groups $(p<0.001)$ in the final test (T2). In the statistical analysis for paired samples, statistically significant differences were observed between the two time points in group I ( $p$ $<0.001)$ and statistically significant differences in group II $(\mathrm{p}<0.05)$. We mark these results with interest as they show us that the level of infatuation has increased significantly in both groups.

In the statistical analysis of the values for self-esteem (SN) for unpaired samples between the two groups, very statistically significant differences were observed in the initial test (T1) $(p<0.01)$ and statistically significantly significant differences in the final test $(T 2) .(p<0.001)$. In the statistical analysis for paired samples, statistically significant differences were observed between the two time points in both group I and group II ( $p$ $<0.001)$. 
Vlad Teodor GROSU, et al. | Lumen Proceedings 17 | WLC 2021

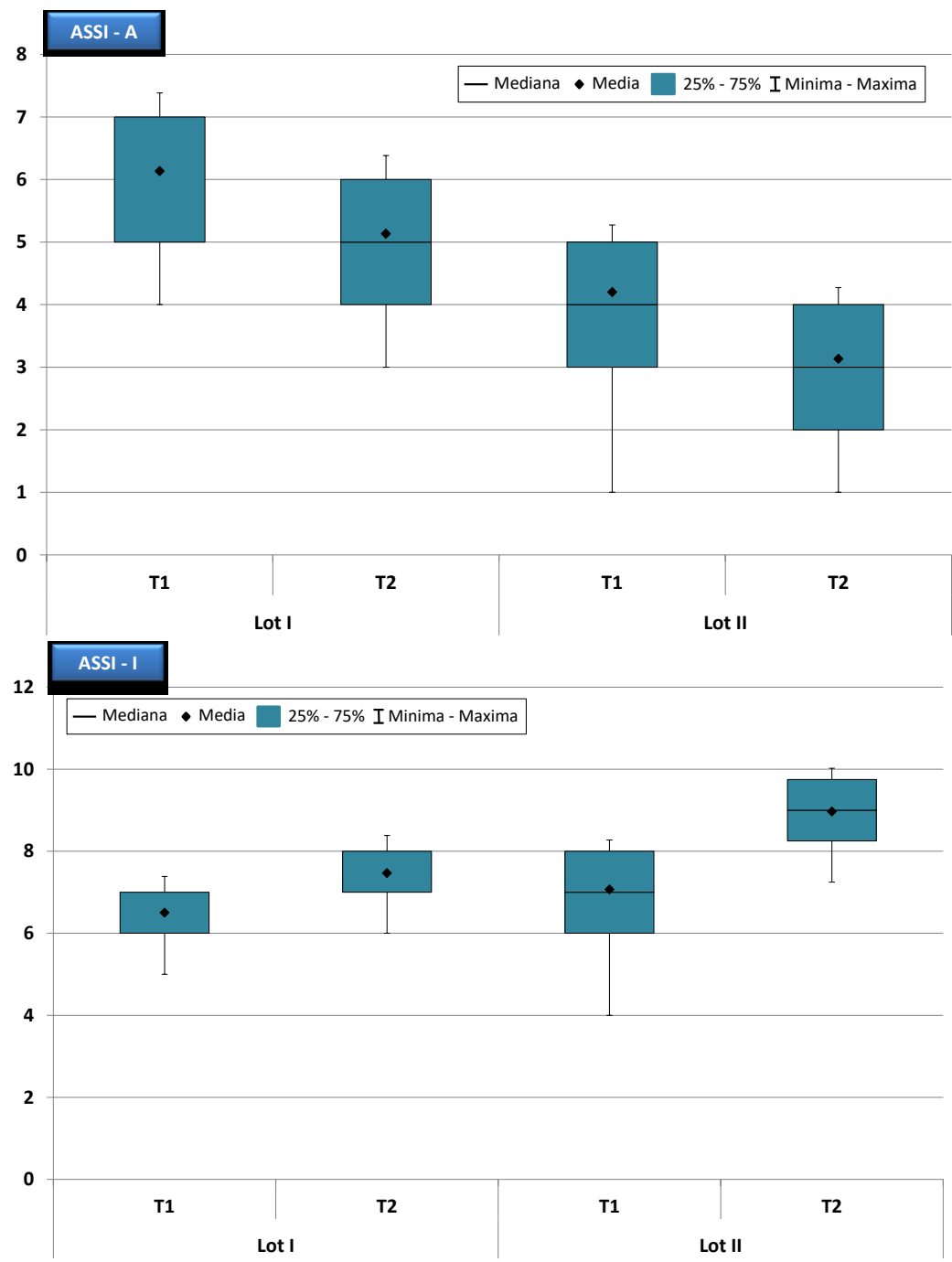

Fig. 10. Relation in the ASSI test of Auto depreciation at T1 and T2 (left) Fig. 11. Relation in ASSI test of the Infatuation at T1 and T2 (right)

We therefore find that self-esteem improved in both groups, as expected if we measured low values in the self-depreciation item (A), but it should be noted that in the experimental group in the final test (T2) the differences are much higher. Statistical analysis of the correlation between the values of the ASSI test items showed, as can be seen below. In lot I: an acceptable but opposite correlation between A-I, where the value of the A-I ratio from -0.3249 at the initial test (TI) will reach the value -0.2275 at the final test (T2), fig. 10, 11 
- An acceptable and similar correlation between I-SN at the initial test (TI) and the value of 0.3642 at the final test (T2) reaches the value of 0.3170. In group II: a good but opposite correlation between A-SN, where the initial test (TI) is -0.5215 and at the final test (T2) it reaches 0.1488 - An acceptable and similar correlation between I-SN, at the initial test (TI) is 0.3282 , and at the final test (T2) is 0.2554 , fig. 12

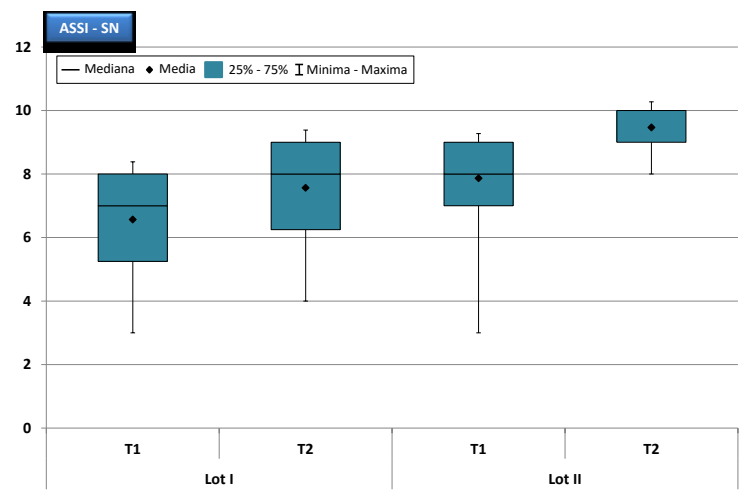

Fig. 12. Relation of the ASSI test of (SN) self-confidence

Table 2. Statistical analysis of correlation between the values of the ASSI questionnaire

\begin{tabular}{llll}
\hline \multirow{3}{*}{ Lot I } & A-I & $-0,3249$ & $* *$ \\
& A-SN & $-0,1756$ & $*$ \\
& I-SN & 0,3642 & $* *$ \\
\hline \multirow{3}{*}{ Lot II } & A-I & $-0,0837$ & $*$ \\
& A-SN & $-0,5215$ & $* * *$ \\
& I-SN & 0,3282 & $* *$ \\
\hline
\end{tabular}

We can observe in Lot II between the values (A) self-depreciation and (SN) self-esteem a very good correlation of -0.5215 .

Table 3. Statistical analysis of correlation between the item values of the ASSI questionnaire

\begin{tabular}{llllll}
\hline Lot & Indicatori & Timp 1 & & Timp 2 \\
\hline \multirow{3}{*}{ I } & A-I & $-0,3249$ & $* *$ & $-0,2275$ & $*$ \\
& A-SN & $-0,1756$ & $*$ & $-0,1414$ & $*$ \\
& I-SN & 0,3642 & $* *$ & 0,3170 & $* *$ \\
\cline { 2 - 7 } II & A-I & $-0,0837$ & $*$ & $-0,0925$ & $*$ \\
& A-SN & $-0,5215$ & $* * *$ & 0,1448 & $*$ \\
& I-SN & 0,3282 & $* *$ & $\mathbf{0 , 2 5 5 4}$ & $* *$ \\
\hline
\end{tabular}


In group I, we have the following results: At $2 * *$ there is an acceptable correlation but of the opposite direction between A-I, which means if (A) self-depreciation decreases then (I) infatuation increases. The value of the A-I ratio from -0.3249 at the initial test (T1) will reach the value -0.2275 at the final test (T2). At $2 * *$ the I-SN case is an acceptable correlation and of the same meaning between I-SN and at the initial test (T1), the value of 0.364 and the final test (T2) reaches the value 0.3170 , which means that the ratio between (I) infatuation and (SN) self-esteem remains approximately identical.

In group II, we have the following results: in case $1 * \mathrm{~A}-\mathrm{I}$ is a good correlation but of opposite direction between A-SN. At 3 *** the A-SN case is a good correlation but of the opposite direction, which means that if (A) self-depreciation decreases then (SN) self-esteem increases. The values of $0.5215 \mathrm{~T} 1$ following the implementation of the intervention programs through dance and music reach T2 at a value of 0.1488 . This shows that the intervention programs were well planned and dosed in the plan. At $2 * *$ the I-SN case is an acceptable correlation and of the same meaning, which means that if (I) the infatuation increases and (SN) the self-esteem increases.

Discussions: statistically significant differences were observed in the indicators of the ASSI tests (self-depreciation, self-esteem, infatuation) which indicates, that our intervention program in the preliminary study had a positive and measurable impact on students in terms of improving selfdepreciation and infatuation, as well as increasing self-esteem. The dancetherapy theory is based on the principle that the mind and body interact. Therefore, the therapist-client relationship is based in part on non-verbal cues, such as body language (Dobrescu, 2006). Improvisation of movements allows the client to experience new ways of being, and dance-therapy provides a way or channel in which the client can consciously understand early relationships with negative stimuli through non-verbal mediation by the therapist (Levy, 1988).

Conclusions of the ASSI questionnaire: the figures of the results of the ASSI questionnaire are more than encouraging as they show us that our intervention program had a positive influence in improving the studied indicators. Subjects increased their self-esteem and infatuation scores and decreased self-depreciation scores. Given these results, we conclude that so far, our hypotheses are confirmed by validating the tests used and the intervention program, which has largely achieved the desired impact. By uniting body, mind and spirit, dance therapy provides a sense of integrity for all individuals (Grosu, E., F., \& Padilla, C., 2011). The body discharges energy through musculoskeletal reactions to stimuli received from the brain. The mind refers to mental activities such as memory, imagery, perception, 
attention, reasoning and decision making. Dance movement brings many benefits to our health both physically and mentally regardless of age. In contemporary postmodern societies, the self is less and less predictable, unstable, present in the multitude of social values. The postmodern self appears to be subject to dilemmas that Giddens (2010) conceptualizes as follows: in contemporary societies, reflective self-profiling, which can plan life coherently and assume uncertainty and seek specialized help in crisis situations, own existence. The constituents of self-image include the following elements: the evolution of performance, one's own opinion about failures and achievements, the impression left on others (friends, relatives, teachers, coaches, colleagues, etc.) and school results (Giddens, 2010).

Limitations of the research: not all students were able to perform exactly the specific elements of dance present in the intervention program, the movements leaving room for improvement in some subjects, but we believe that this does not influence the results obtained as the entourage and atmosphere it was ensured, thus giving the possibility of psychic improvements, the objectives that were targeted in our research.

\section{References}

Adams, G. \& Berzonsky, M. (2009). Psibologia adolescenţei, Manualul Blackwell. Iaşi: Ed. Polirom

Allet L., Muller-Pinget S., (2017). Dance therapy combined with patient education improves quality of life of persons with obesity: A pilot feasibility study for a randomized controlled trial. Obes Res Clin Pract., 11(1), 79-87. https://doi.org/10.1016/i.orcp.2016.03.005

Candela, M., Conte, R., Pastena, N. (2013). The role of dancing in the Educational process. Procedia - Social and Behavioral Sciences, 106, 3069-3074.

Chelcea, S. (2006). Opinia publică: strategii de persuasiune și manipulare. Bucureşti: Editura Economică.

Constantin T., (2004). Memoria autobiografică; definirea sau redefinirea propriei vieți. Editura Institutului European, Iaşi.

Davis W., Gfeller, K., Thaut, M. (2008). An introduction to music therapy: theory and practice (Third ed.), Silver Spring, Maryland: American Music Therapy Association.

Dewhurst, S., Nelson, N. (2014). Scottish country dance: benefits to functional ability in older women. National Institutes of Health, January, 146-53.

Dobrescu, T. (2006). Dimensiuni ale comunicării prin limbajul corpului. Editura Tehnopress, Iaşi. 
Vlad Teodor GROSU, et al. | Lumen Proceedings 17 | WLC 2021

Duberg, A., (2012). Dancing and the brain - Department of Neurobiology. JAMA

Pediatrics. Available at: https://dancecoquitlam.ca/wp-

content/uploads/2014/11/Dancing-and-the-Brain.pdf

Ekman, S., Bengtsson, P., Winblad, B. (1998). Social and Motor Functioning in Persons with Dementia. Journal of Psychiatric and Mental Health Nursing, 545554.

Giddens, A. (2010). The Rise and Fall of New Labour. New Perspective Quarterly, 27(3), 32-37.

Giovagnoli, A. R., Oliveri, S. (2013). Active music therapy improves cognition and behaviour in chronic vascular encephalopathy: A case report. Complementary Therapies in Medicine, 22(1), 57-62.

Goffman, E. (1961). Asylums: Essays on the social situation of mental patient and other inmates. New York: Anchor Books.

Grosu E. F., Padilla, C. (2011). Elementele tehnicii corporale şi gimnastica artistică, ritmică şi dans. Editura GMI, Cluj - Napoca

Grosu, E. F. (2009). Elemente de tehnică corporală. Editura GMI, Cluj - Napoca.

Guilbert, L. (2000). Dancer avec le IIIe Reich: les danseurs allemandes sous le Nazism. Brussels: Complexes.

Hackett, S., Morison, C.-J., \& Pullen, C. (2013). A retrospective practice based evaluation of music therapy: A single-case study of a four-year-old girl with Rett syndrome-Rebecca's story. The Arts in Psychotherapy, 40(5), 473-477.

Harter, S. (1998). The development of self-representations. In W. Damon \& N. Eisenberg (Ed.), Handbook of child psychology: Social, emotional, and personality development (pp. 553-617). Hoboken, NJ, US: John Wiley \& Sons Inc

Humphreys, T. (2007). Stima de sine. Cheia pentru vïtorul copilului tău. Bucureşti: Ed. Elena Francisc.

Iluţ, P. (2001). Sinele şi cunoaşterea lui. Iaşi: Ed. Polirom.

James, R. A. (1980). A circumplex model of affect. Journal of Personality and Social Psychology, 39(6), 1161-1178.

Levy, F. (1988). Dance Movement Therapy: A Healing Art. Reston, VA: The American Alliance for Health, Physical Education, Recreation and Dance.

Owens, T. (1993). Accentuate the positive and the negative: rethinking the use of self-esteem, self-deprecation, and self-confidence. Social Psychology, 40, 521531.

Rocha P. A., Slade S. C. (2017). Dance is more than therapy: Qualitative analysis on therapeutic dancing classes for Parkinson's. Complementary Therapies in Medicine, 34, 1-9.

Rosenberg, M. (1979). Components of Rosenberg's self-esteem scale. Conceiving the self. New York: Basic Books. 
Vlad Teodor GROSU, et al. | Lumen Proceedings 17 | WLC 2021

Schore, A. (1994). Affect regulation and the origin of the self: neurobiology of emotional development. Journal of the American Academy of Child \& Adolescent Psychiatry, 35.

Taylor, S. E., Brown, J. D. (1994). Positive illusions and well-being revisited: Separating fact from fiction. Psychological Bulletin, 116(1), 21-27. 